\title{
HIGH SPECIFICITY OF AUTOMATED RESPIRATORY CYCLE SELECTION FOR CALCULATION OF RESPIRATORY MECHANICS
}

\author{
V. Rigo ${ }^{1}$, E. Graas ${ }^{2}$, J. Rigo $^{1}$ \\ ${ }^{1}$ Neonatology, University of Liège, CHU de Liège (CHR), ${ }^{2}$ Nomics, Liège, Belgium
}

Background: Selected optimal respiratory cycles allow calculation of respiratory mechanics (RM) parameters focusing on patient-ventilator interaction.

Methods: Ten ventilated newborns recordings (10 minutes, SIMV and AC) were analyzed. Ventilator provided RM data (VRC) every ten seconds. Pressure (P), flow (V') and volume (V) waves, and PV, PV' and $\mathrm{V}^{\prime} \mathrm{V}$ loops were reconstructed from continuous $\mathrm{P}$ and $\mathrm{V}^{\prime}$ recording. Visual assessment determined assisted leak-free optimal respiratory cycles (SRC, selected cycles). New computer software automatically graded cycles' quality (ARC, automatic cycles). RM values were derived from optimal cycles. We evaluated automated selection quality and compared RM parameters according to ventilatory mode and dataset.

Results: 11724 cycles are evaluated. ARC/SRC selections agreement is high: Kappa with linear weighting is $0.76 \pm 0.005$ ( $88 \%$ of maximal kappa). Specificity and positive predictive values are 0.98 and 0.96 . Averaged values are similar between ARC and VRC, but C20/C decreases marketly. $\mathrm{V}_{\mathrm{T}}$ apparent similarity disappears in AC: ARC $\mathrm{V}_{\mathrm{T}}(4.8 \pm 1.0 \mathrm{~mL} / \mathrm{kg})$ is significantly lower than for VRC $(5.6 \pm 1.8 \mathrm{~mL} / \mathrm{kg})$. Coefficients of variation decrease for all ARC parameters.

\begin{tabular}{|l|l|l|}
\hline Mean & ARC & VRC \\
\hline $\mathrm{R}(\mathrm{hPa} / \mathrm{L} / \mathrm{s})$ & $120 \pm 48$ & $125 \pm 52$ \\
\hline $\mathrm{C}(\mathrm{mL} / \mathrm{hPA} / \mathrm{kg})$ & $0.416 \pm 0.111$ & $0.449 \pm 0.160$ \\
\hline $\mathrm{VT}(\mathrm{mL} / \mathrm{kg})$ & $5.0 \pm 0.9$ & $5.0 \pm 1.5$ \\
\hline $\mathrm{C} 20 / \mathrm{C}$ & $1.27 \pm 0.37^{*}$ & $1.81 \pm 0.67$ \\
\hline [Table 1] & & \\
\hline
\end{tabular}

Conclusions: Automated selection is highly specific. ARC respiratory cycles reflect most the action of both ventilator and patient. Averaged parameters derived from ARC are more accurate and could be displayed by ventilators. 